\title{
Reversed Microstructures and Tensile Properties after Various Cold Rolling Reductions in AISI 301LN Steel
}

\author{
Antti Järvenpää ${ }^{1, *(\mathbb{D})}$, Matias Jaskari ${ }^{1}$ (D) and Leo Pentti Karjalainen ${ }^{2}$ \\ 1 Kerttu Saalasti Institute, Future Manufacturing Technology Group, University of Oulu, Pajatie 5, \\ FI-85500 Nivala, Finland; matias.jaskari@oulu.fi \\ 2 Centre for Advanced Steels Research, University of Oulu, P.O. Box 4200, FI-90014 Oulu, Finland; \\ pentti.karjalainen@oulu.fi \\ * Correspondence: antti.jarvenpaa@oulu.fi; Tel.: +358-(0)-445-551-633
}

Received: 10 January 2018; Accepted: 2 February 2018; Published: 6 February 2018

\begin{abstract}
Heavy cold rolling is generally required for efficient grain size refinement in the martensitic reversion process, which is, however, not desirable in practical processing. In the present work, the influence of cold rolling reductions of $32 \%, 45 \%$ and $63 \%$ on the microstructure evolution and mechanical properties of a metastable austenitic AISI 301LN type steel were investigated in detail adopting scanning electron microscopy with the electron backscatter diffraction method and mechanical testing. A completely austenitic microstructure and a partially reversed counterpart were created. It was found that the fraction of grains with a size of $3 \mu \mathrm{m}$ or larger, called medium-sized grains, increased with decreasing the prior cold rolling reduction. These grains are formed mainly from the shear-reversed austenite, transformed from slightly-deformed martensite, by gradual evolution of subgrains to grains. However, in spite of significant amounts of medium-sized grains, the tensile properties after the $32 \%$ or $45 \%$ cold rolling reductions were practically equal to those after the $63 \%$ reduction. The austenite stability against the formation of deformation-induced martensite in subsequent straining was reduced by lowering the cold rolling reduction, due to the larger grain size of medium-sized grains and the shift of their orientation towards $\{211\}<\mathrm{uvw}>$.
\end{abstract}

Keywords: austenitic stainless steel; cold rolling reduction; reversion treatment; grain size; tensile properties; austenite stability

\section{Introduction}

Grain-refined austenitic stainless steels are an interesting group of materials from a scientific, but also commercial, point of view, due to their excellent combination of high strength and good ductility achievable in annealed condition. In numerous papers, martensitic reversion has been shown to be an effective method for refining the grain size of metastable austenitic stainless steels, including commercial grades, such as AISI types 304, 301, 301LN, 201LN and 204Cu [1-5]. Submicron-sized grains are formed during short annealing, while deformation-induced martensite (DIM) transforms into austenite. However, as demonstrated by Tomimura et al. [6] in 1991, and later, e.g., by Takaki et al. [7] and Misra et al. [8,9], highly-deformed cell-type martensite is a prerequisite source of a large number of nucleation sites for new austenite grains to attain this ultrafine grain size. A low degree of deformation of martensite tends to result in lath-type martensite, which transforms into austenite with morphological characteristics of the parent phase, with a coarser structure. In studies targeting efficient grain size refinement, high cold rolling (CR) thickness reductions in the range of $60-90 \%$ have commonly been applied, e.g., [10-14], or cryorolling at subzero temperatures $[1,2,13,15,16]$, multi-step rolling schedules $[12,17]$, or very unstable high-Mn low-Cr alloys have been designed, such as those shown in $[18,19]$. 
Recent studies have revealed that the marked heterogeneity of the reversed austenitic structure affects its stability in subsequent monotonic and cyclic loading [20,21]. Slightly-deformed martensite and the presence of retained deformed austenite (DA) after low CR reductions tend to modify the structure, resulting in non-homogeneous grain size distributions inherited from reversed DIM and recrystallized DA. Hence, the grain structure, especially that obtained at low annealing temperatures, which provides the highest strength with good ductility, is often quite complex. Heterogeneous structures have been investigated and discussed by Poulon-Quintin et al. [11], Ravi Kumar et al. [22], Kisko et al. [23] and, most recently, by Järvenpää et al. [20], but only after heavy CR reductions (60\% or above).

Complex processing routes are not desired in practice, so interest should be focused on microstructures and properties achievable while using feasibly lower CR reductions, such as $50 \%$ or even less. Thickness reductions of $45-60 \%$ were applied by Rajasekhara et al. [14] for 301LN, Somani et al. [3] and Misra et al. [24] for 301 and 301LN, and 60\% by Kisko et al. [5] for low-Ni Cr-Mn types, 201 and 204Cu austenitic stainless steels. Promisingly, in a 301LN steel, even after CR reductions as low as $45 \%$ submicron size, austenite seemed to form during the reversion process [3]. The reversion kinetics were found to be strongly dependent on the prior deformation and annealing conditions $[3,6]$.

Hence, due to these preliminary indications, the feasibility of low CR reductions should be studied in more detail to better understand their influence on the above-mentioned microstructural features and mechanical properties attained. In the present study, the effects of CR reductions of $32 \%$ (i.e., lower than in the previous studies), $45 \%$ and $63 \%$ on the fully reversed, and for the first time, also on partially reversed structures and their mechanical properties were investigated in $301 \mathrm{LN}$ steel. Further, the stability of the reversed structures under tensile loading is reported here.

\section{Materials and Methods}

\subsection{Test Material}

The test material was a commercial austenitic $18 \mathrm{Cr}-7 \mathrm{Ni}-0.15 \mathrm{~N}$ stainless steel of the type 301LN, received from Outokumpu (Outokumpu Oy, Tornio, Finland), as an $8 \mathrm{~mm}$ hot rolled and annealed sheet. The chemical composition, determined at the company using an ARL 4460 optical emission (Thermo Fisher, Waltham, MA, USA) and ARL 9800 XP X-ray spectrometers (Thermo Fisher, Waltham, MA, USA), is given in Table 1. For the reversion treatments, the sheet was cold rolled to three different final thicknesses in a laboratory rolling mill, so that the total CR thickness reductions were about $32 \%, 45 \%$ and $63 \%$-the samples coded as $32 \mathrm{CR}, 45 \mathrm{CRand} 63 \mathrm{CR}$, respectively. In order to find out the influence of the CR reduction on the DIM fraction, some additional reductions were applied. After each rolling pass, the sheets were cooled to room temperature in an environmental chamber, using a gas flow of liquid nitrogen, controlled by a thermostat.

Table 1. Chemical composition (wt.\%) of the steel studied. The balance is Fe.

\begin{tabular}{cccccccccccc}
\hline $\mathbf{C}$ & $\mathbf{S i}$ & $\mathbf{M n}$ & $\mathbf{P}$ & $\mathbf{S}$ & $\mathbf{C r}$ & $\mathbf{N i}$ & $\mathbf{M o}$ & $\mathbf{C u}$ & $\mathrm{Al}$ & $\mathbf{O}$ & $\mathbf{N}$ \\
\hline 0.025 & 0.53 & 1.25 & 0.024 & 0.001 & 17.5 & 6.5 & 0.09 & 0.20 & 0.014 & 0.004 & 0.15 \\
\hline
\end{tabular}

\subsection{Reversion Heat Treatments}

Rectangular pieces of $20 \mathrm{~mm} \times 200 \mathrm{~mm}$ were cut from the cold rolled sheet transverse in the rolling direction (RD). The pieces were reversion heat treated on a Gleeble 3800 thermo-mechanical simulator (Dynamic Systems Inc., Poestenkill, NY, USA) before machining specimens for mechanical testing. A high heating rate of $200{ }^{\circ} \mathrm{C} / \mathrm{s}$ and cooling rate of $35^{\circ} \mathrm{C} / \mathrm{s}$ were adopted. The annealing temperature and holding time applied were $900{ }^{\circ} \mathrm{C}$ and $1 \mathrm{~s}$, and $750{ }^{\circ} \mathrm{C}$ and $0.1 \mathrm{~s}$, to create the desired two microstructures-a completely reversed austenitic and a partially reversed structure-coded based on the annealing temperature and holding time being 900-1 and 750-0.1, respectively. These 
structures, after the $63 \%$ CR reduction, were investigated previously and the latter structure exhibits the highest strength among the structures studied [20,21]. However, the partially reversed structure contains some retained DIM which disturbs observations concerning the nucleation sites of new DIM in tensile straining, so that also an austenitic structure without any retained DIM, but otherwise closely resembling the 750-0.1 structure, was created by annealing at $800{ }^{\circ} \mathrm{C}$ for $10 \mathrm{~s}$ after the $32 \% \mathrm{CR}$ reduction (coded 800-10-32CR). To study the early state of the reversion, some 32CR and 63CR samples were annealed at a lower temperature of $700{ }^{\circ} \mathrm{C}$ for $0.1 \mathrm{~s}$ or $1 \mathrm{~s}$. Some data from earlier experiments were used as references to demonstrate the differences with coarse-grained and ultrafine-grained austenite structures [20,21].

\subsection{Mechanical Testing and Sample Preparation}

The heat-treated pieces were machined for tensile testing. The width and the length of the gauge section was 6 and $25 \mathrm{~mm}$ respectively, and the thickness, depending on the CR reduction, was 5.5, 4.4 and $3.4 \mathrm{~mm}$ for the 32CR, 45CR and 63CR sheets, respectively. Tensile straining was performed in a Zwick100 tensile testing machine (Zwick Roell Group, Baden-Württemberg, Ulm, Germany), equipped with an external extensometer. A low strain rate $(0.00051 / \mathrm{s})$ was applied to avoid any adiabatic heating. Microhardness (the load $0.25 \mathrm{~N}$ ) of the austenite with different grain sizes and DIM was measured using a CSM MHT-Z-AE tester (CSM Instruments SA I A company of Anton Paar, canton of Neuchâtel, Peseux, Switzerland) with a Vickers indenter. The measurement was repeated ten times in each location to obtain an average value.

Specimens for metallography, X-ray diffraction and hardness testing were first fine ground to 600 grit and then electropolished before gentle oxide suspension polishing to avoid any martensite transformation during sample preparation.

\subsection{Microstructure Examinations}

Specimens were examined using a scanning electron microscope (Zeiss Ultra Plus, Carl Zeiss AG, Oberkochen, Baden-Württemberg, Germany) with an electron backscatter diffraction (EBSD) unit (Zeiss-Oxford Instruments, $15-20 \mathrm{kV}$, aperture $120 \mu \mathrm{m}$, working distance 10-12 mm and the minimum step size of $0.03 \mu \mathrm{m}$ ). The area for the EBSD examinations varied because the magnification and step size were chosen so that at least 10,000 grains were covered in an image. The views on the cross-sections (the RD-normal to sheet surface plane) were taken close to the sheet surface, about $0.1-0.2 \mathrm{~mm}$ below the edge.

Oxford instruments' Aztec and HKL software (Aztec version 3.0 SP1, Oxford Instruments, Oxfordshire, Abingdon, UK), was used for acquiring and quantifying the EBSD data. For identifying different phases, three crystallographic structures were adopted from the Aztec software databases: iron (bcc) for $\alpha^{\prime}$ martensite, iron (fcc) for austenite, and Fe (hcp) for epsilon martensite. To identify the phases, the standard lattice parameters were adopted from the Oxford database. The austenite was interpreted as three different states: ultrafine-grained austenite reverted by diffusion or shear mechanisms, or as deformed and recovered retained austenite. Kernel average misorientation maps were not utilized, but the different states were defined from the size of grains or the band contrast and grain boundary maps.

For post-processing the data, HKL Channel5 software (Channel5 version 5.12.56.0, Oxford Instruments, Oxfordshire, Abingdon, UK) including Tango was used. The cleanup of the collected data was performed by using the standard noise reduction algorithm so that at least six neighbouring points needed to be present, and less than $10 \%$ of the indexed points were altered.

Grain sizes were measured as the circle equivalent diameter parameter, defining $15^{\circ}$ as the critical misorientation for high angle grain boundaries and $0.2 \mu \mathrm{m}$ as a minimum grain size. For grain boundary maps that also revealed the recovery, a critical misorientation of $2.5^{\circ}$ was defined for low angle grain boundaries. In this work, microtexture analysis was not performed but few conclusions concerning the special grain orientations were drawn simply from inverse pole figures (IPF). 
The evolution of the ferromagnetic $\alpha^{\prime}$-martensite fraction, i.e., DIM, was determined during interrupted tensile tests using a Feritscope instrument (Feritscope FMP30, Helmut Fischer GmbH Institut für Elektronik und Messtechnik, Sindelfinge, Germany), with a correction factor of 1.7, as specified by Talonen et al. [25] and Beese and Mohr [26]. This method provided more consistent data than the EBSD due to non-homogeneity of the microstructure. The magnetic measurements were carried on specimens unloaded at different strains to avoid the Villari effect [26].

The X-ray diffraction (XRD) method with Rietveld WPPF (whole powder pattern fitting) analysis was applied using Rikagu SmartLab equipment (Rigaku corporation, Akishima, Tokyo, Japan) and Co $\mathrm{K}$ radiation ( $40 \mathrm{kV}$ and $40 \mathrm{~mA}$ ), to determine the martensite fractions after the CR reductions of $32 \%$ and beyond. A Feritscope instrument was employed at the lower reductions. The volume fraction of non-magnetic epsilon martensite was supposed to be always low (a few percent maximum), as earlier observed in tensile testing [25] as well as in stress-controlled fatigue testing of this steel [4]. However, in EBSD examinations, it was recorded as an hcp-phase.

\section{Results and Discussion}

\subsection{Initial Grain Structures}

\subsubsection{Cold Rolled Microstructure}

In the metastable 301LN steel, the austenite phase only transformed partially to martensite in the cold rolling stage. The DIM fractions are plotted as a function of the CR reduction under the present conditions in Figure 1, determined by a Feritscope (after the lowest reductions) and XRD (after the high reductions). The DIM fractions were $70 \%, 89 \%$ and $96 \%$ for the $32 \mathrm{CR}, 45 \mathrm{CR}$ and $63 \mathrm{CR}$ sheets, respectively, as measured on the sheet surfaces (Figure 1 and Table 2). This means that these microstructures contained a decreasing amount of DA-30\%, $11 \%$ and $4 \%$, respectively. The grain size of the DA was coarse-approximately $23 \mu \mathrm{m}$. It can be mentioned that the DIM contents measured on the cross-sections of the samples tended to be slightly higher, indicating higher amounts of martensite at the sheet centerline region, as shown and discussed earlier [20,21].

It is important to note that the formation of DIM in this steel did not saturate or reach $100 \%$ at the $45 \%$ reduction. From the curve in Figure 1, it can be estimated that about $30 \%$ of new DIM was formed while the CR reduction increased from $22 \%$ to $32 \%$. This means that in the $32 \mathrm{CR}$ sheet, $30 \%$ DIM encountered a deformation degree of $10 \%$ or less. Correspondingly, quantities of about $17 \%$ and $7 \%$ of new DIM were formed while the CR degree increased from $35 \%$ to $45 \%$ and $53 \%$ to $63 \%$, respectively. Hence, quantities of $17 \%$ and $7 \%$ of DIM were deformed by a reduction of $10 \%$ or less in the $45 \mathrm{CR}$ and 63CR structures, respectively. These amounts are much less than in the $32 \mathrm{CR}$ sheet, i.e., the fraction of "slightly-deformed DIM"- which plays a significant role in microstructure evolution, as shown in the following sections-increases with a decreasing CR reduction.

The deformation structures of some metastable austenitic stainless steels have been examined in detail by transmission electron microscopy (TEM), so that further TEM work would hardly provide much new information and was not performed. Tomimura et al. [27] investigated an $\mathrm{Fe}-16 \mathrm{Cr}-10 \mathrm{Ni}$ steel after $10 \%$ and $90 \% \mathrm{CR}$ reductions, and Takaki et al. [7] investigated an $\mathrm{Fe}-18 \mathrm{Cr}-8.6 \mathrm{Ni}$ alloy after $50 \%$ and $90 \%$ reductions. Later Rajasekhara et al. [14] and Misra et al. [8] examined a similar 301LN steel to the present steel after the CR reductions of $45 \%, 62 \%$ and $77 \%$. In all these studies, it was found that two types of DIM existed-lath-type and cell-type-the fraction of the cell type increasing with an increased CR reduction. The DIM formed by $10 \%$ cold rolling was needle-like, consisting of blocks in the lath martensitic structure. The block size was $4-5 \mu \mathrm{m}$ in width and about $10 \mu \mathrm{m}$ in length. With further deformation of DIM itself, the lath structure changed to cell-type by the formation of a high number of slip bands. In Section 3.1.3, the importance of the type of the cold rolled martensite will become apparent. 


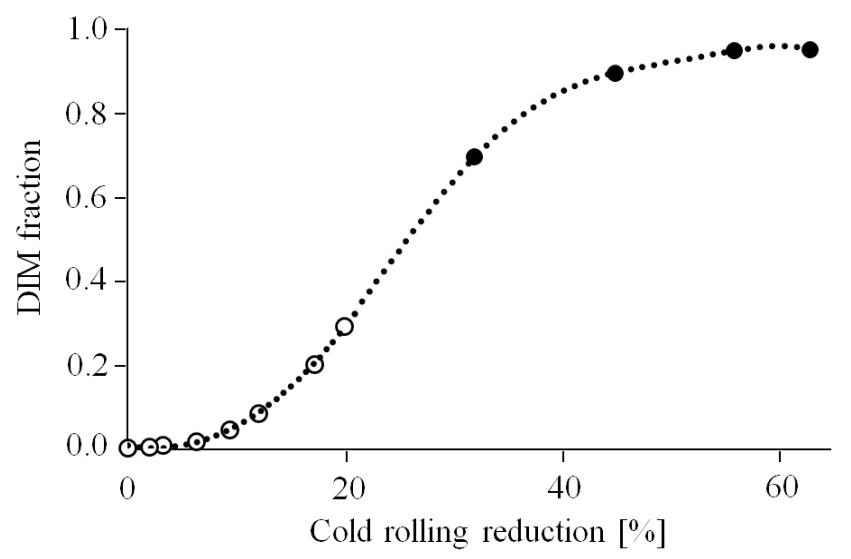

Figure 1. The evolution of the deformation-induced martensite (DIM) fraction in a 301LN under the present cold rolling conditions. Open symbols are results from Feritscope and solid from X-ray diffraction (XRD) measurements.

Table 2. Grain sizes and phase fractions of the studied structures.

\begin{tabular}{ccccccccc}
\hline \multirow{2}{*}{ Structure } & \multicolumn{9}{c}{ Grain Size } & \multicolumn{7}{c}{ Phase Fractions } \\
\cline { 2 - 9 } & \multicolumn{2}{c}{$(\boldsymbol{\mu m})$} & \multicolumn{1}{c}{$\mathbf{( \% )}$} \\
\cline { 2 - 9 } & AGS & SD & RA & SD & DA & SD & DIM & SD \\
\hline 32CR & $23^{*}$ & 15 & 0 & 0 & 30 & 1.4 & 70 & 2.0 \\
45 CR & $23^{*}$ & 15 & 0 & 0 & 11 & 2.1 & 89 & 2.4 \\
63CR & $23^{*}$ & 15 & 0 & 0 & 4 & 4.5 & 96 & 2.2 \\
$900-1-32 C R$ & 3.4 & 3.1 & 100 & 0 & 0 & 0 & 0 & 0 \\
$900-1-45 C R$ & 2.1 & 1.3 & 100 & 0 & 0 & 0 & 0 & 0 \\
$900-1-63 C R$ & 1.4 & 1.4 & 100 & 0 & 0 & 0 & 0 & 0 \\
$750-0.1-32 C R$ & 1.2 & 1.1 & 61 & 5.1 & 30 & 3.6 & 9 & 5.8 \\
$750-0.1-45 C R$ & 0.8 & 0.8 & 81 & 4.9 & 11 & 4.9 & 8 & 3.9 \\
$750-0.1-63 C R$ & 0.6 & 0.6 & 94 & 0.6 & 4 & 0.6 & 2 & 1.0 \\
\hline
\end{tabular}

AGS, average grain size; CR, cold rolling; RA, reversed austenite; DA, deformed austenite; DIM, deformation-induced martensite; SD, standard deviation; * Measured by EBSD from a hot rolled sheet.

\subsubsection{Reversed Microstructures}

Two different initial microstructures-the fully austenitic structure and partially reversed structure-were processed for each $\mathrm{CR}$ stage, by varying the annealing temperature and soaking time $\left(900{ }^{\circ} \mathrm{C}\right.$ or $750{ }^{\circ} \mathrm{C}$ and $1 \mathrm{~s}$ or $0.1 \mathrm{~s}$, respectively). Typical structures are displayed in Figure 2 in a superimposed EBSD phase and grain boundary maps. The average grain sizes and the standard deviations, determined for more than 10,000 grains, based on the high angle grain boundaries; the misorientations higher than $15^{\circ}$; and the phase fractions, are listed in Table 2. The structures created at $900{ }^{\circ} \mathrm{C}$ within $1 \mathrm{~s}$ were equiaxed, all DIM was reversed and DA recrystallized. The average grain size decreased with increasing the $C R$ reduction, from 3.4 to $1.4 \mu \mathrm{m}$ (Figure 2a,c,e). In the 750-0.1 structures, the DA grains were not yet recrystallized, but, as an indication of recovery, a low EBSD image quality and substructure could be seen in them (Figure $2 b, d, f)$. Also a few percent of DIM were retained-not transformed to austenite yet. This amount was around $8-9 \%$ in the 32CR and 45CR structures, but less in the 63CR structure (Table 2), although local variation was prominent. Also, the average grain size of the 750-0.1 structure decreased from 1.2 to $0.6 \mu \mathrm{m}$ with an increase in the CR reduction. 


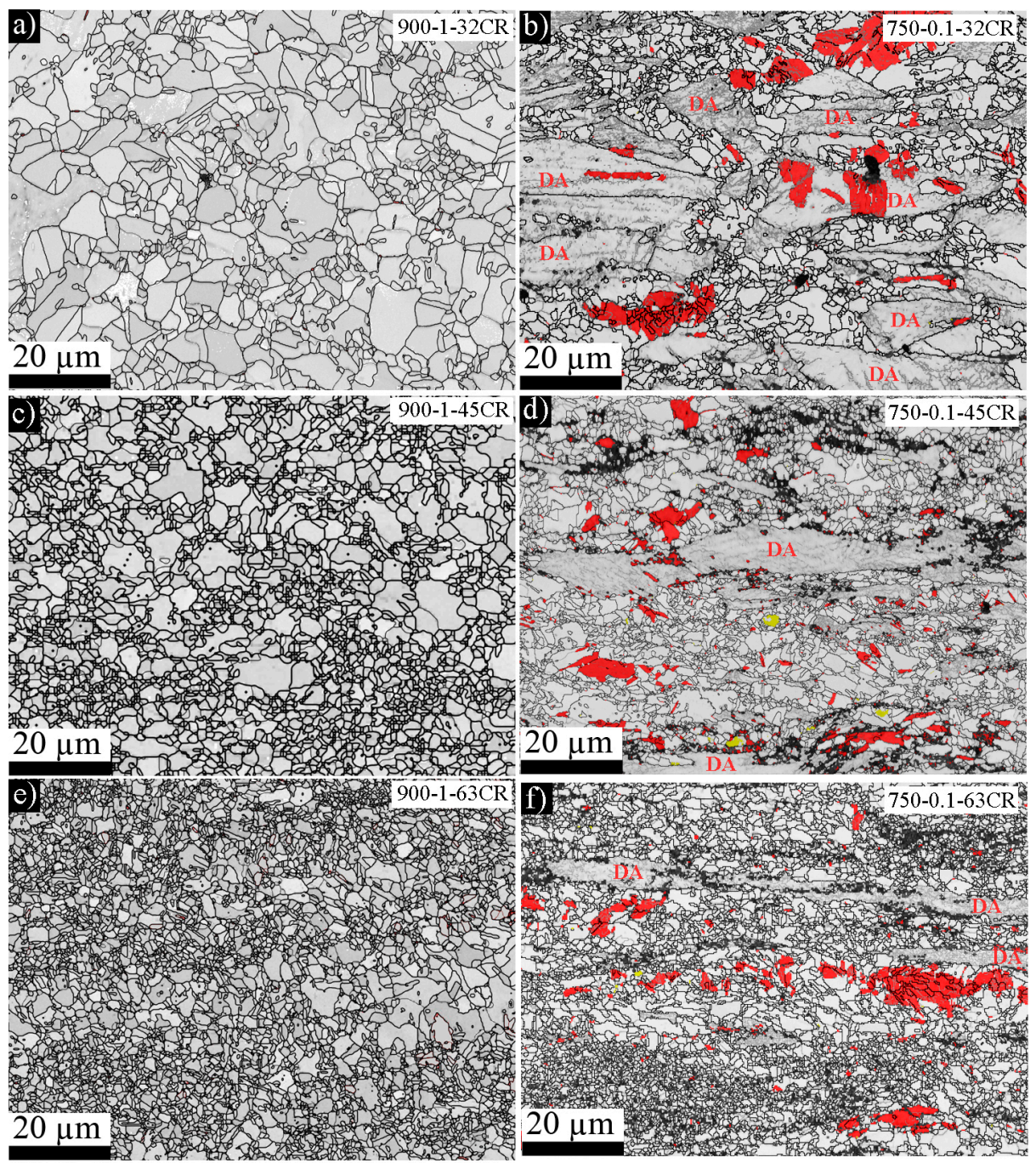

Figure 2. Initial structures (electron backscatter diffraction (EBSD) image; cross-sectional view near the surface) (a) 900-1-32CR, (b) 750-0.1-32CR, (c) 900-1-45CR, (d) 750-0.1-45CR, (e) 900-1-63CR, (f) 750-0.1-63CR revealing differences in the grain size and phase structures after different cold rolling $(\mathrm{CR})$ reductions. Retained DIM as red and epsilon martensite in yellow in $(\mathbf{b}, \mathbf{d}, \mathbf{f})$. Retained deformed austenite is marked as deformed austenite (DA).

However, the average grain size is not a good characteristic of these non-homogeneous structures. Clearly a few micron-sized-called medium-sized grains hereafter-and submicron-sized reversed austenite grains could be seen in both the 900-1 and 750-0.1 structures. In addition, the latter structure also contains coarse, obviously dislocated austenite grains. The background of the pronounced inhomogeneity of reversed structures was discussed in detail earlier, in relation to the $63 \% \mathrm{CR}$ structures [20]. In order to characterize the present structures, the area fractions of the reversed grains, with sizes below and above $3 \mu \mathrm{m}$, but excluding the coarse gray DA grains in the 750-0.1 structures, were counted from the EBSD data and plotted in a diagram in Figure 3. The number of grains included was about 10,000. 


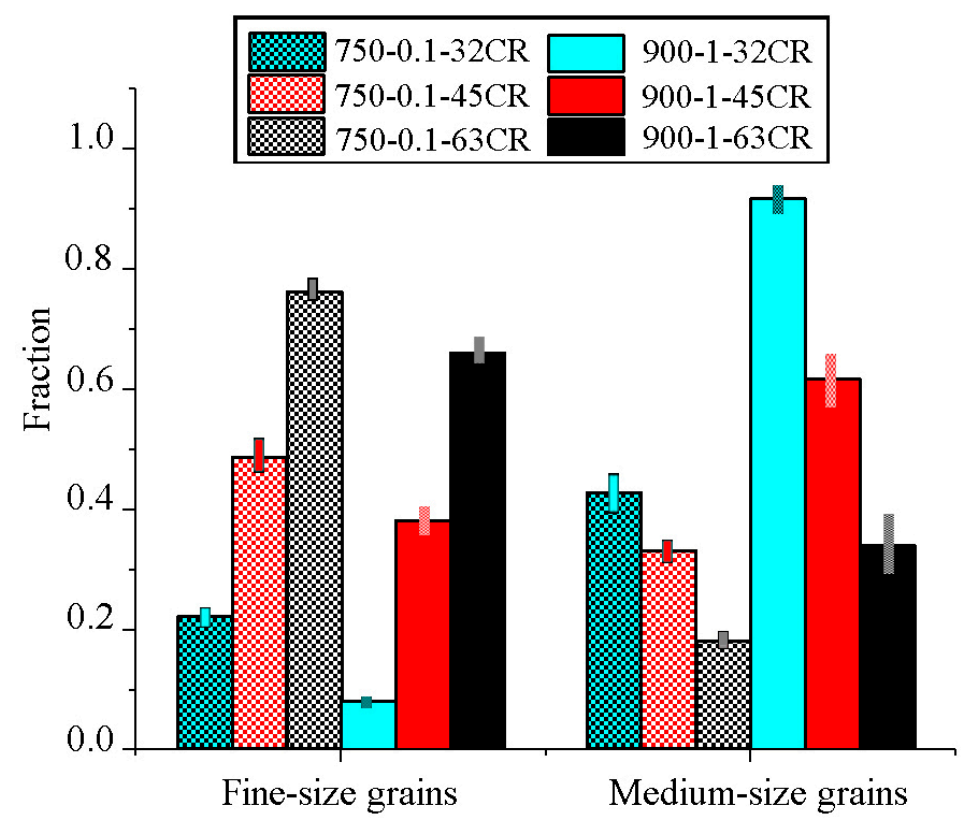

Figure 3. Grain size distributions (area fractions) of the reversed structures. Fine-sized grain $(<3 \mu \mathrm{m})$ and medium-sized grain $(\geq 3 \mu \mathrm{m})$.

It is seen that the area of fine-sized grains increases and that of medium-sized grains decreases with an increase in the $C R$ reduction in both structures. At a given $C R$ reduction, the area fraction of fine-sized grains is higher and that of medium-sized ones is lower in the 750-0.1 structure than in the 900-1 structure. For example, in the 63CR structures, the area fraction of medium-sized grains was $18 \%$ in the 750-0.1 structure, in comparison to $34 \%$ in its 900-1 counterpart.

The 750-0.1 structures also contained very coarse dislocated austenite grains which look gray in Figure $2 b, d, f$. The DA was recovered and naturally belongs to this class of grains. However, a relevant question is whether there was also austenite formed by the shear mechanism of the DIM among them. The shear-reversed austenite contains a high density of dislocations, similar to the DA grains [9], so they look very similar and are difficult to distinguish.

The fraction of the gray grains in the 750-0.1 structure was determined using image analysis (colored black, as shown in Figure 4). According to the analysis, the area fractions of the black grains were $35 \%, 19 \%$ and $3 \%$ for the $32 \%, 45 \%$ and $63 \%$ CR reductions, respectively. These values correspond roughly to the fractions of DA after the cold rolling (Table 2), the differences being only $5 \%, 8 \%$ and $0 \%$, respectively. Hence, it seems that the amount of sheared austenite is small in this structure. However, we have to realize that a higher amount of coarse shear-reversed austenite might exist initially, before changing to finer austenite grains, as will be shown in the following section.
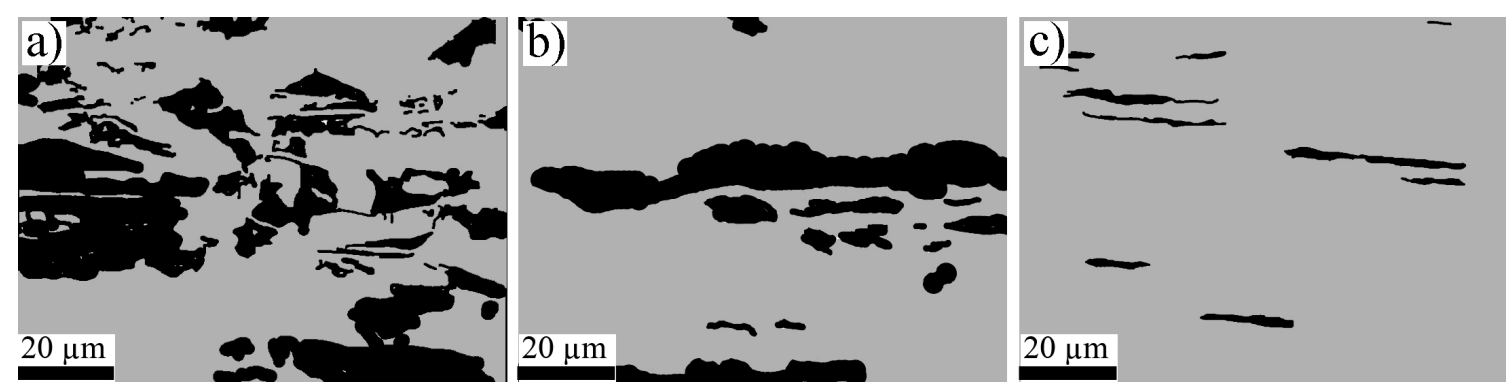

Figure 4. DA grains, colored in black, for the analysis of their fraction (see Figure $2 b, d, f$ ) in (a) 750-0.1-32CR, (b) 750-0.1-45CR and (c) 750-0.1-63CR. 


\subsubsection{Early Stages of Reversion}

As will be discussed in Section 3.3, the most unstable austenite grains seem to be medium-sized grains, whereas submicron-sized grains as well as coarse grains exhibit more stable behavior. The origin and formation mechanisms of the medium-sized grains are of interest. No substructure could be detected in the medium-sized grains in EBSD images (see Figure 2). In the 900-1 structure, these grains can originate from the reversion of DIM at a relatively high annealing temperature as well as from recrystallization of DA grains. In the 750-0.1 structure, recrystallization of DA grains did not occur, however. The origin of these grains is more unclear and therefore, this was further investigated by annealing a few 32CR and $63 \mathrm{CR}$ samples at a lower temperature of $700{ }^{\circ} \mathrm{C}$ for short holding times of $0.1 \mathrm{~s}$ and $1 \mathrm{~s}$. The objective was to observe the early stages of the formation of the partially reversed structure.

The superimposed phase and grain boundary maps, after heating up to $700{ }^{\circ} \mathrm{C}$ and holding for $0.1 \mathrm{~s}$ and $1 \mathrm{~s}$, are shown in Figures 5 and 6, respectively. In Figure 5a, we can hardly detect any medium-sized grains, and in Figure 5b, an image taken from another location, few medium-sized grains exist between coarse-grained austenite grains. Hence, the first medium-sized grains have formed locally in this stage. In these figures, submicron-sized grains cannot be seen, which indicates that under these conditions the medium-sized grains start to form earlier than the submicron-sized grains do.

Following the annealing at $700{ }^{\circ} \mathrm{C}$ for $0.1 \mathrm{~s}$, the DIM fraction of the $32 \mathrm{CR}$ sample, determined by XRD, was $39 \%$. Before this annealing, the DIM fraction was $70 \%$ (Figure 1), which means that during this very short treatment, 31\% DIM had already transformed (Figure $5 a, b)$. The fraction of medium-sized grains was estimated to be $6 \%$, although varying significantly locally. This means that the fraction of coarse austenite grains was $55 \%$. After the CR stage, the fraction of DA was only $30 \%$, so that the remaining $25 \%$ of coarse grains must be formed from DIM by the shear mechanism. Comparing the 700-0.1-32CR structure (Figure 5a,b) with the 750-0.1-32CR structure (Figure 2b), we notice that there are not so many coarse grains in the latter one, but instead, many more medium-sized grains. Thus, a conclusion can be drawn that the medium-sized grains form from the coarse-grained austenite, either from the shear-reversed austenite or from DA.

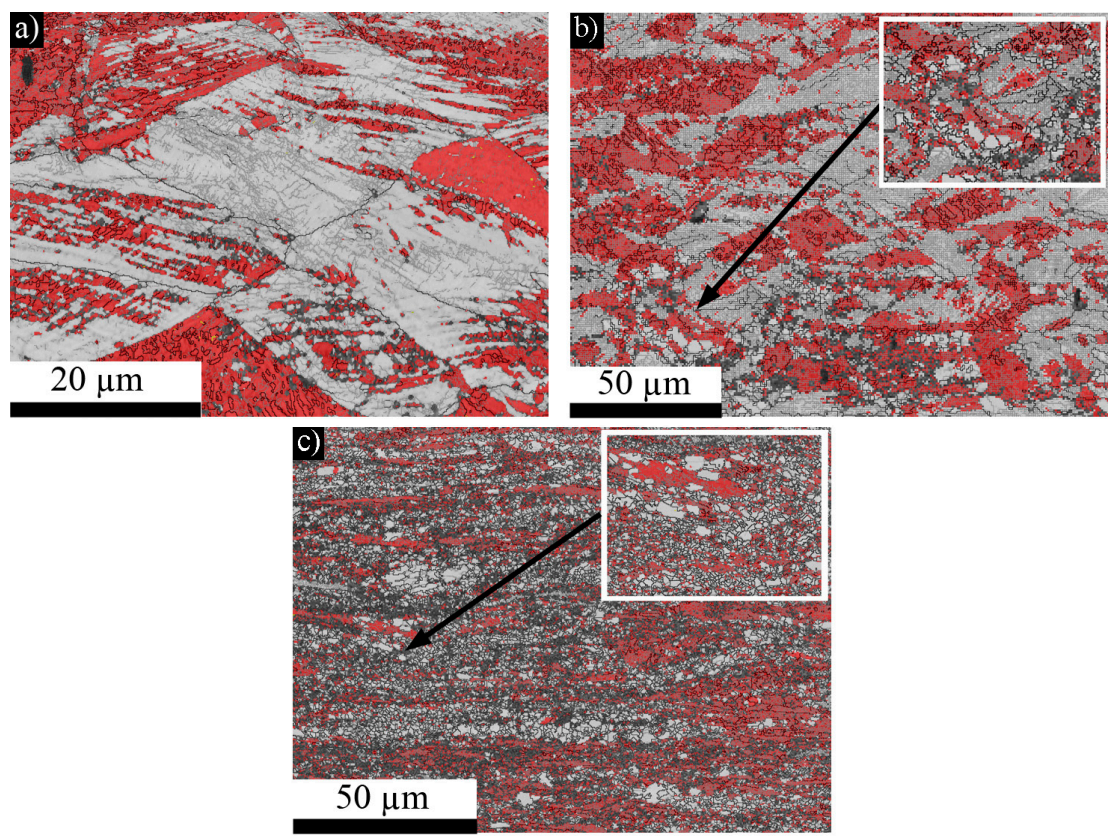

Figure 5. EBSD phase and grain boundary maps of the $32 \mathrm{CR}(\mathbf{a}, \mathbf{b})$ and $63 C R$ (c) structures after annealing at $700{ }^{\circ} \mathrm{C}$ for $0.1 \mathrm{~s}$. DIM is colored in red; austenite is colored in gray. The inserts display, more clearly, medium-sized grains. 

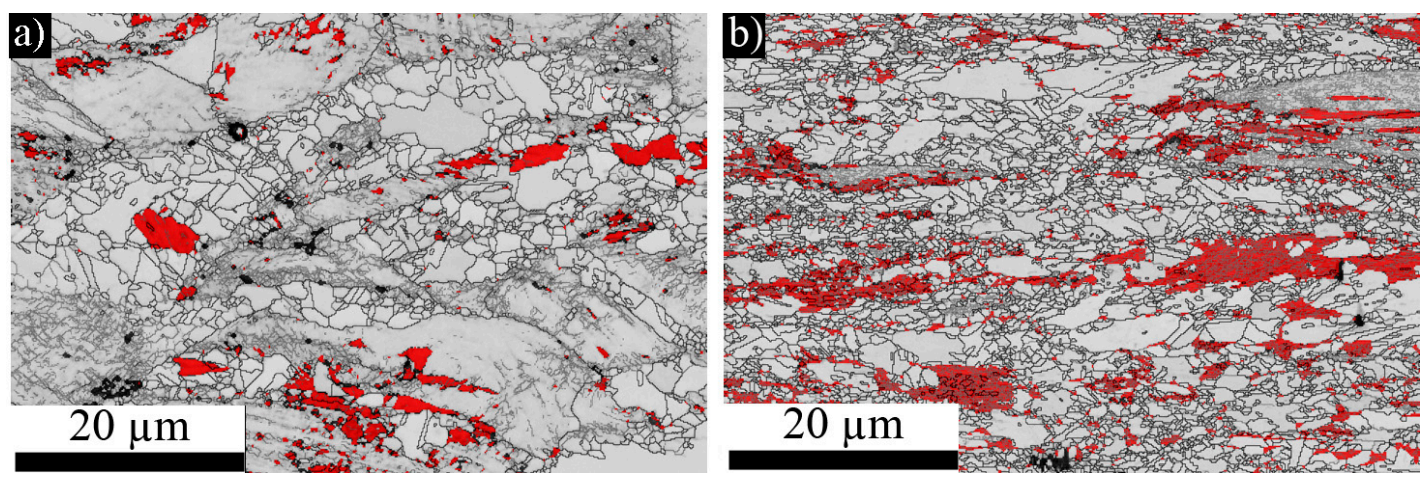

Figure 6. Phase and grain boundary maps (DIM colored in red) after $1 \mathrm{~s}$ holding at $700{ }^{\circ} \mathrm{C}$ (a) $32 \mathrm{CR}$ and (b) 63CR. Medium-sized and submicron-sized grains with retained DIM and DA.

The DIM fraction formed in $63 \% \mathrm{CR}$ reduction was $96 \%$. After $0.1 \mathrm{~s}$ at $700{ }^{\circ} \mathrm{C}$ (Figure $5 \mathrm{c}$ ), the DIM fraction, determined by XRD, was $48 \%$, which means that the half of the DIM had reversed. This is more than in the $32 \%$ CR structure, i.e., the CR reduction affects the reversion rate. We can observe that now, the reversed structure consists of both submicron-sized and medium-sized grains, in addition to a few coarse grains. The number of medium-sized grains is much higher (estimated as $18 \%$ ) than in the $32 \mathrm{CR}$ structure (6\%). Hence, the submicron-sized grains and more medium-sized grains have appeared due to the higher applied CR reduction. The submicron-sized grains have formed, without doubt, by the diffusional mechanism $[3,8,9]$, and earlier, we concluded that the medium-sized grains form from the coarse-grained austenite. Because the fraction of DA was only $4 \%$ after the $63 \%$ CR reduction, a major part, or all of the medium-sized grains, formed from the shear-reversed austenite. This indicates that both the diffusional and shear mechanisms are active under these conditions. The simultaneous operation of both mechanisms-though the diffusional is the major one-was found earlier, by the present authors, after annealing at $700-800{ }^{\circ} \mathrm{C}[20,21]$, and also by Kisko et al. [23], who observed both mechanisms in a 204Cu type $\mathrm{Cr}-\mathrm{Mn}$ steel at low annealing temperatures.

The evolution of the reversion process during annealing is revealed by comparing Figure 5 with Figure 6 , the structures after $0.1 \mathrm{~s}$ and $1 \mathrm{~s}$ holding at $700{ }^{\circ} \mathrm{C}$, respectively. Due to prolonged holding, the retained DIM fraction decreased from $39 \%$ to about $10 \%$. In the 32CR structure, the fraction of medium-sized grains has become significant (Figure 6a), and in the 63CR structure, the areas of two different grain sizes are clearly visible-submicron-sized as well as medium-sized grains (Figure 6b). It may be noticed that quite a similar structure is seen in Figure $2 \mathrm{f}$, i.e., after $0.1 \mathrm{~s}$ at $750{ }^{\circ} \mathrm{C}$ with $19 \%$ of the medium-sized grains and large areas of the submicron-sized grains.

The submicron-sized grains have been shown to form by diffusional reversion directly from DIM $[3,8,9]$, but how do the medium-sized grains nucleate? They could also form directly from DIM by diffusional reversion, and/or from shear-reversed austenite, or also from DA. However, the fraction of DA is small, especially in the 63CR structure, so it is not high enough for any significant amount of formation of medium-sized grains. Takaki et al. [7] showed that in $18 \mathrm{Cr}-9 \mathrm{Ni}$ steel, after a $50 \%$ cold working reduction, leading to slight deformation of DIM, the stratum structure of austenite laths and blocks was formed by the diffusional mechanism, forming a lath-martensitic structure. In the present case, the typical shape of medium-sized grains is slightly flattened with multiple corners (see Figure $2 \mathrm{a}, \mathrm{d}, \mathrm{f})$, so that they might resemble martensitic blocks. The substructure inside them could never be detected, anyhow.

It was noticed from microstructure images that the medium-sized grains form from large dislocated grains. Two examples of this kind of nucleation are illustrated in Figure 7 (such areas also exist in Figures 2, 5, 6a and 10c). It is seen that the dislocations have rearranged to create a subgrain structure in the recovery process. Then, some of the subgrains adjacent to high-angle boundaries first evolve to dislocation-free areas, which will be separated by a high-angle grain boundary later. This is the mechanism found in TEM examinations of shear-reversed austenite, and called "coalescence of 
subgrains" by Tomimura et al. [27], "lattice rotation or cell boundary merging" by Lee et al. [28], and "gradual evolution of subgrains and their subsequent transformation into fine grains by a continuous recrystallization type process" by Ravi Kumar and Sharma [22].
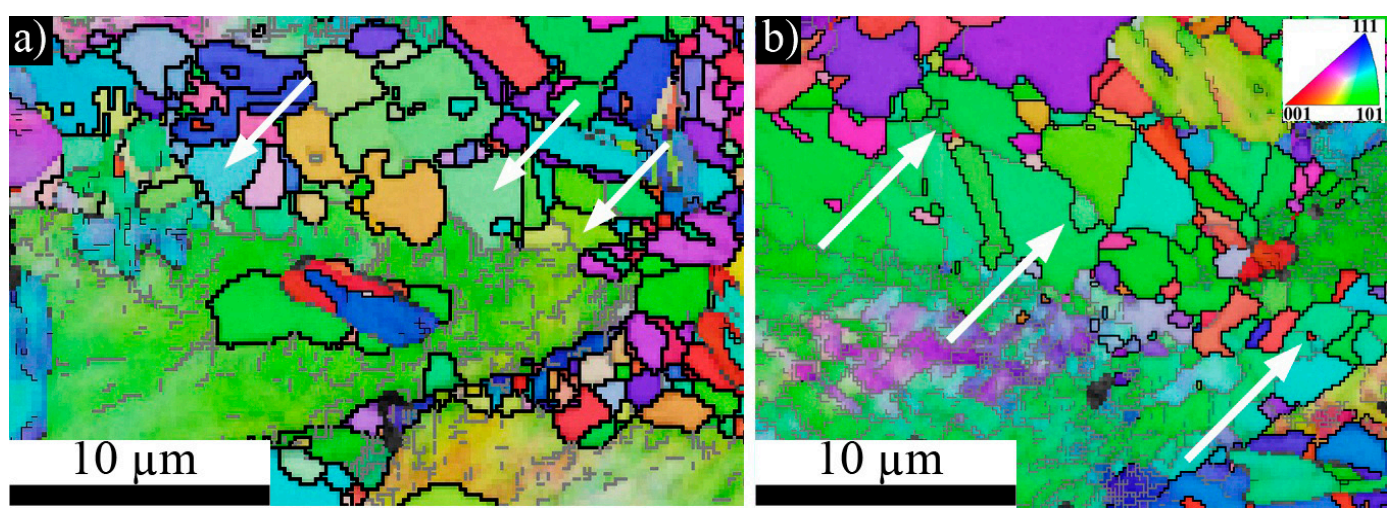

Figure 7. Two examples $(\mathbf{a}, \mathbf{b})$ of the formation of medium-sized grains from shear-reversed DIM by gradual evolution of subgrains in 750-0.1-32CR (shown by arrows). EBSD inverse pole figures (IPF) overlap with grain boundary maps. High-angle grain boundaries are black; low-angle grain boundaries gray.

We can ask why the grain size (GS) is non-homogeneous in the reversed structure, consisting of medium-sized grains in addition to submicron-sized grains, and in increasing amounts with the decreasing CR reduction (Figure 3). An obvious explanation is that the submicron-sized grains are formed from the heavily-deformed cell-type martensite and the medium-sized grains from the slightly-deformed lath-type martensite. It has been shown by TEM examinations that the type of deformed martensite affects the reversed austenite grain size [7-9]. The fraction of medium-sized grains is increasing with a decreasing CR reduction, because of the increased fraction of slightly deformed martensite, as concluded earlier from Figure 1. Thus, in order to obtain submicron-sized structures, a high CR reduction beyond $60 \%$ is essential. But do we need such structures if a high tensile strength is required? This will be considered in the following section.

\subsection{Tensile Properties}

Tensile tests were carried out to determine the effect of the CR reduction on tensile properties in the two reversion-treated conditions. The results, based on 3-6 repetitions, are shown in Figure 8 and listed in Table 3. It is seen first that the engineering ultimate tensile strength was slightly $(\sim 10 \%)$, and the yield strength significantly $(\sim 70 \%)$, higher in the 750-0.1 structure than in its 900-1 counterpart, whereas both the uniform and total elongation were approximately $17 \%$ units lower in the former than in the latter structure. The influence of annealing temperature on tensile properties has been investigated in numerous previous studies, e.g., [3,24,29]. However, importantly, any significant effect of the degree of CR reduction (32-45-63\%) on the tensile properties could not be found. In the 750-0.1 structure, this means that the contribution of the decreasing fraction of submicron-sized grains seems to be balanced, or even slightly exceeded, by the increasing fraction of the cold rolled and recovered DA, medium-sized grains and retained DIM. This can be understood on the basis of the strength of different microstructural features in the structure. 

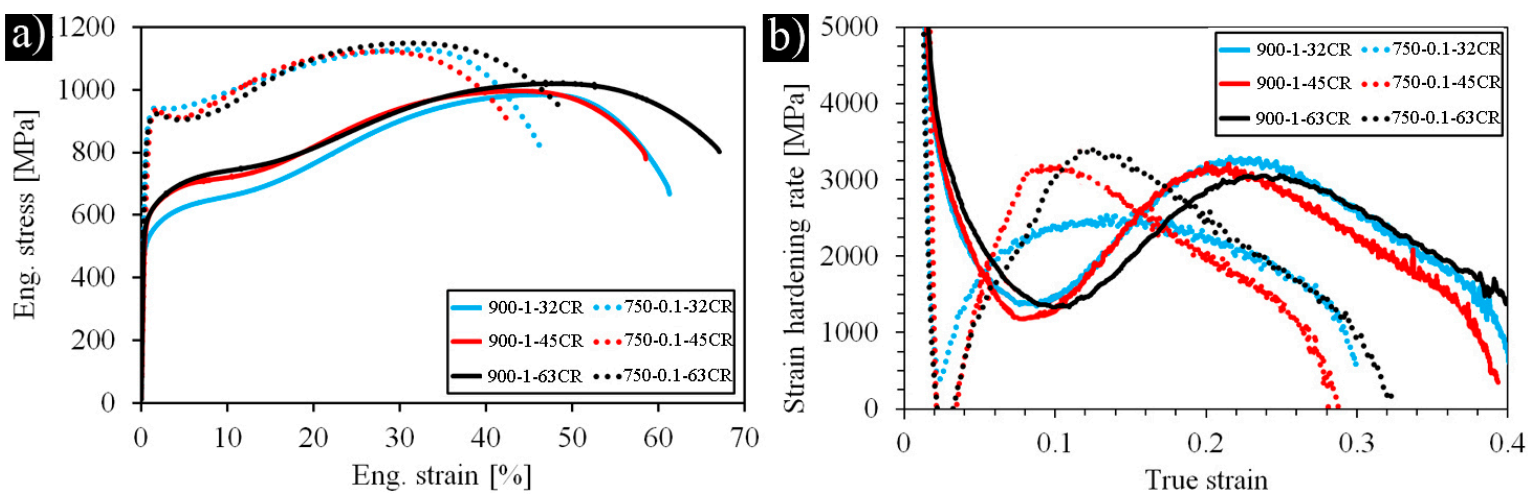

Figure 8. Engineering stress-strain curves (a) and strain hardening curves (b) for the structures.

Table 3. Tensile test properties of the studied structures.

\begin{tabular}{|c|c|c|c|c|c|c|c|c|}
\hline \multirow{2}{*}{ Structure } & YS & SD & UTS & SD & UEl & SD & TEl & SD \\
\hline & \multicolumn{4}{|c|}{ (Mpa) } & \multicolumn{4}{|c|}{$(\%)$} \\
\hline $32 \mathrm{CR}$ & 1260 & 17 & 1480 & 8 & 5 & 0.4 & 19 & 1.2 \\
\hline $45 \mathrm{CR}$ & 1480 & 27 & 1670 & 32 & 2 & 0.8 & 14 & 0.6 \\
\hline $63 C R$ & 1770 & 7 & 1840 & 3 & 2 & 0.2 & 5 & 3.1 \\
\hline 900-1-32CR & 490 & 6 & 990 & 11 & 47 & 1.1 & 61 & 1.6 \\
\hline 900-1-45CR & 550 & 6 & 1000 & 18 & 45 & 0.8 & 60 & 0.5 \\
\hline 900-1-63CR & 550 & 8 & 1025 & 15 & 47 & 4.0 & 67 & 2.8 \\
\hline 750-0.1-32CR & 940 & 14 & 1130 & 20 & 31 & 0.9 & 46 & 0.3 \\
\hline 750-0.1-45CR & 900 & 11 & 1150 & 40 & 28 & 1.9 & 42 & 0.9 \\
\hline 750-0.1-63CR & 900 & 23 & 1150 & 13 & 31 & 2.2 & 49 & 4.9 \\
\hline
\end{tabular}

YS, yield strength; UTS, ultimate tensile strength; UEl, uniform elongation; TEl, total elongation; SD, standard deviation.

The microhardness measurements were employed to evaluate the strength of various microstructural features. The hardness of recovered DA was highest (about $400 \mathrm{HV}$ ), the submicron-sized structure medium (about $360 \mathrm{HV}$ ), and the medium-sized grains lowest (about $300 \mathrm{HV}$ ). The fourth feature is the recovered DIM. Thus, variation in the fraction of these multi-features (the analysis is not presented here) is due to the different tensile strengths, but in the end, the influence remains quite insignificant. Hence, it seems that highly enhanced strength properties can be achieved using a CR reduction as low as $32 \%$ and annealing at temperatures around $750{ }^{\circ} \mathrm{C}$.

In the 900-1 structure, the increasing average grain size does reduce the strength values, but the difference in the yield strength seems to be only $60 \mathrm{MPa}$. In fair agreement, Somani et al. [3] reported a difference of $53 \mathrm{MPa}$ in the structures obtained by the CR reductions of $76 \%$ and $45 \%$ while annealing at $750{ }^{\circ} \mathrm{C}$ for $1 \mathrm{~s}$. According to Rajasekhara et al. [29], the coefficient in the Hall-Petch equation for $301 \mathrm{LN}$ steel is $290 \mathrm{MPa} \cdot \mu \mathrm{m}^{1 / 2}$, so that the influence of grain size differences between 3.4 and $1.4 \mu \mathrm{m}$ (Table 3) would be $88 \mathrm{MPa}$.

The strain hardening rate curves are plotted in Figure $8 \mathrm{~b}$. The difference in strain hardening behavior is obvious between the structures, but the CR reduction has a minimal influence on that. In all instances, the strain hardening curve exhibits a peak corresponding to the maximum DIM transformation rate, as shown by the comparison in the next section. The deep minimum and even the softening of the 750-0.1 structure at very low strain is typical to these highly grain-refined structures, especially in the occurrence of precipitation, as reported earlier [20].

\subsection{Austenite Stability}

The evolution in the $\alpha^{\prime}$-martensite (DIM) fraction was measured by a Feritscope instrument on the sheet surface of the specimens, by interrupting the test at certain strains and unloading the specimen. 
Figure 9 reveals the difference between the 900-1 and 750-0.1 structures-the 900- 1 structure being much more stable than the 750-0.1 counterpart at a given CR reduction, in agreement with earlier studies $[20,21]$. The stability of various reversion-treated structures of $63 \%$ cold rolled 301LN steel has been discussed earlier, and the $\mathrm{CrN}$ precipitation was proved to be the controlling factor for the difference [30]. However, no previous data are available concerning the influence of the degree of the CR reduction on the stability. This can be seen in Figure 9a. The lowered CR reduction slightly reduced the stability of the structures. This can be explained as a result of the increasing fraction of medium-sized grains (Figure 3), as will be discussed in the next section. In the 750-0.1 structure, the difference exists for small strains, but not beyond about the 0.18 true strain. DIM formation began at smaller strains in the 32CR and $45 \mathrm{CR}$ structures than in their 63CR counterpart, and the transformation rate, obtained from the slope of the curves in Figure 9a, reached its maximum in the 0.08-0.16 and $0.16-0.24$ strain regimes for the 750-0.1 and 900-1 structures, respectively (Figure $9 \mathrm{~b}$ ).
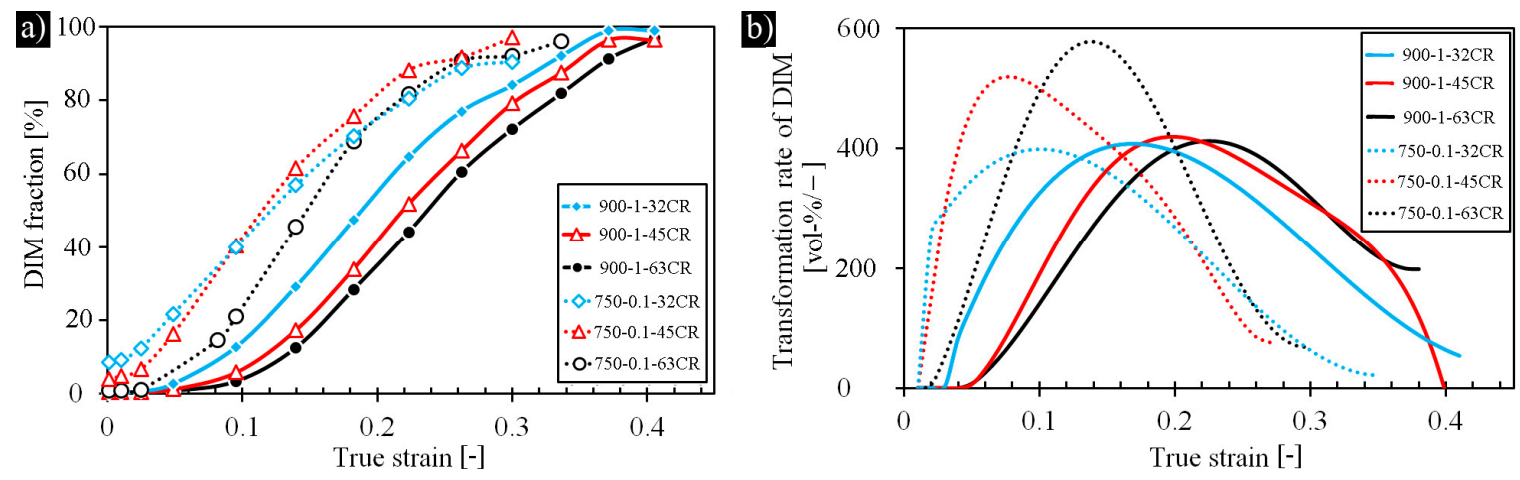

Figure 9. (a) Effect of CR reduction on the evolution of DIM fraction and (b) transformation rate of DIM under tensile straining (transverse to rolling direction).

\subsection{Martensite Nucleation during Tensile Straining}

The start of the DIM transformation in tensile straining was investigated earlier in reversed structures created after the $63 \% \mathrm{CR}$ reduction. As a new topic, the influence of the lower $\mathrm{CR}$ reductions was studied here for the 900-1 and 750-0.1 structures. Figure 10 illustrates the nucleation sites of DIM after exposure to a $7 \%$ engineering strain. It is seen that in the 900-1 and 750-0.1 structures (Figure 10a,b respectively), the new DIM has preferably nucleated inside medium-sized grains. In addition, DIM (small epsilon martensite grains were also present) existed as tiny grains along deformation bands inside some DA grains (Figure 10b), although this fraction remained low. The existence of epsilon martensite as an intermediate phase in the transformation has frequently been observed, e.g., [31]. However, due to retained DIM in the 750-0.1 structure, some uncertainty remains in regard to identifying the first new DIM grains nucleated in tensile straining. Therefore, a few additional specimens were prepared by annealing them at $800{ }^{\circ} \mathrm{C}$ for $10 \mathrm{~s}$ (i.e., creating the $800-10-32 \mathrm{CR}$ structure) when all the DIM from the cold rolling had disappeared. This structure, after the $7 \%$ engineering strain, is shown in Figure 10c, which confirms the observation that DIM is first nucleated in the medium-sized grains as well as along deformation bands in some large recovered DA grains. 

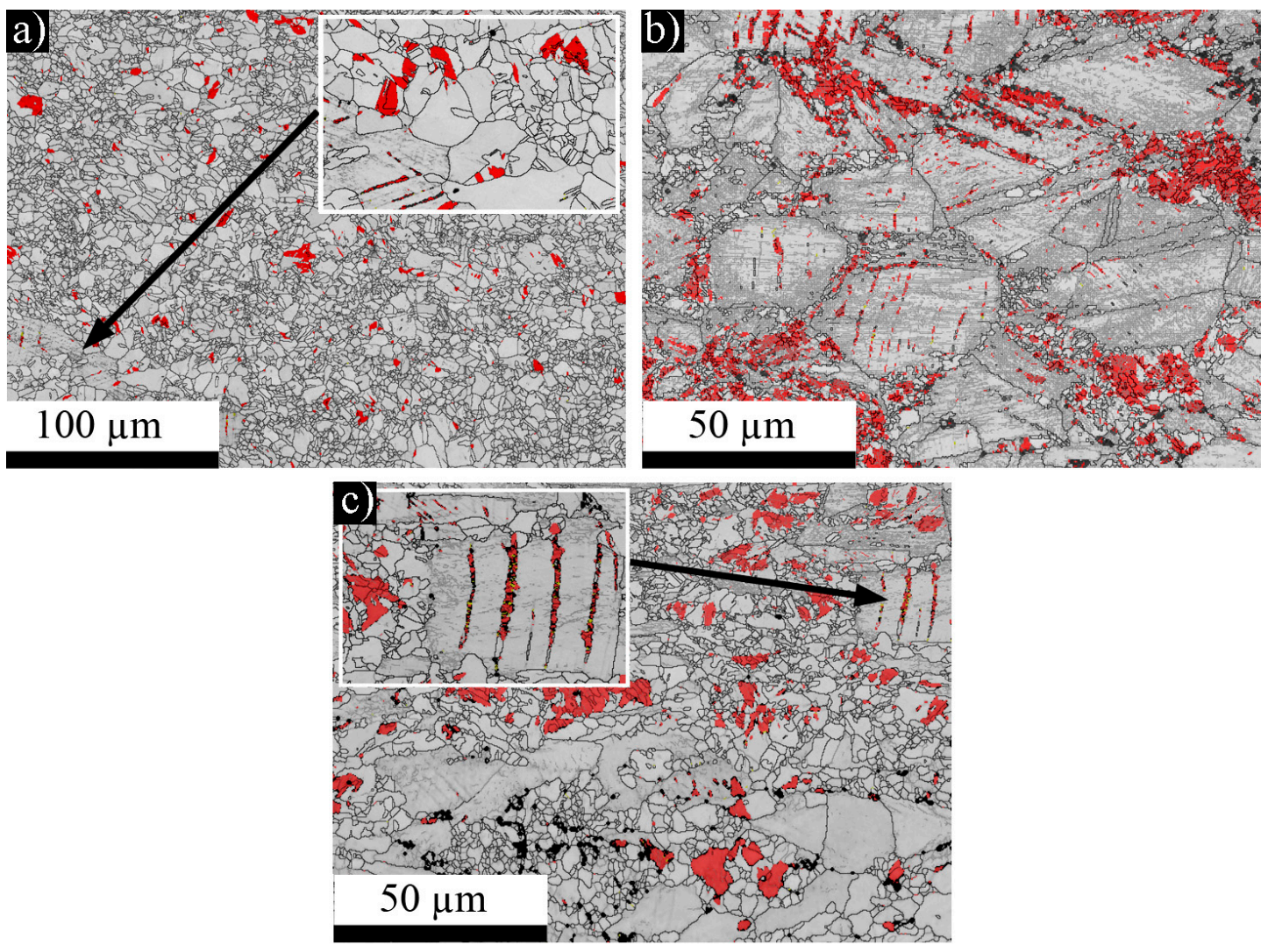

Figure 10. EBSD maps after exposure to $7 \%$ tensile strain. DIM (the red colored phase) in medium-sized grains and some shear bands (a) 900-1-32CR, (b) 750-0.1-32CR, (c) 800-10-32CR. Black spots in (c) are non-indexed areas.

Thus, the medium-sized grains seem to be most susceptible to DIM transformation in tensile straining, which can be explained by their larger grain size than that of the submicron-sized grains formed from the heavily-deformed martensite. In addition, their orientation also has an influence, as pointed out in the next paragraph. The fraction of medium-sized grains is highly dependent on the degree of $C R$ reduction, which explains the stability dependence on $C R$ reduction. At a low reduction, a large fraction of DIM will be deformed only slightly and therefore, tends to revert to medium-sized grains. As seen from Figure 3, the fraction of medium-sized grains is lower in the 750-0.1 structure than in the 900-1 structure, so all medium-sized grain will be consumed during the DIM formation earlier in the former structure, and the influence of the CR reduction disappears at higher strains, as was seen in Figure 9a, in the instance of the 750-0.1 structure.

Finally, we can ask which medium-sized grains are most susceptible to DIM transformation. Obviously, the orientation of the grains has an influence on this. Figure 11 shows a local area of $900-1-32 \mathrm{CR}$ and $800-10-32 \mathrm{CR}$ structures after the exposure to $7 \%$ tensile strain (Figure 11a,b respectively). A small amount of DIM has formed in this stage and the comparison between the phase map and the corresponding orientation (IPF) image reveals that the first DIM has transformed most frequently in reddish and bluish grains, i.e., between $\{100\}<\mathrm{uvw}>$ and $\{111\}<\mathrm{uvw}>$ oriented grains, such as $\{211\}<u v w>$. Only very few green grains have partly transformed (Figure 11a). It has been shown that the $\{110\}<112>$ Brass-type oriented grains (green in the IPF images) are most resistant to DIM formation $[11,20]$, so they tend to remain austenitic. It is well known that at small deformations, all fcc-metals show the Copper-type texture, which is represented by four main ideal crystallographic orientations $\{110\}<100>\mathrm{G}$ (Goss), $\{110\}<112>\mathrm{B}$ (Brass), $\{124\}<634>\mathrm{S}$ and $\{112\}<111>\mathrm{C}$ (Copper), whereas the Brass- and Goss-type texture components dominate at high $\mathrm{CR}$ reductions in austenitic stainless steels [32-34]. The reversed austenite inherits the CR texture $[3,20,34]$. Thus, lower CR 
reductions favor more unstable austenite orientations in the reversed structures and therefore, it can be expected that a lower CR reduction means a lower austenite stability, as observed. This seems to be the second factor, in addition to the amount of medium-sized grains, reducing the stability of the austenitic structure at low CR reductions.

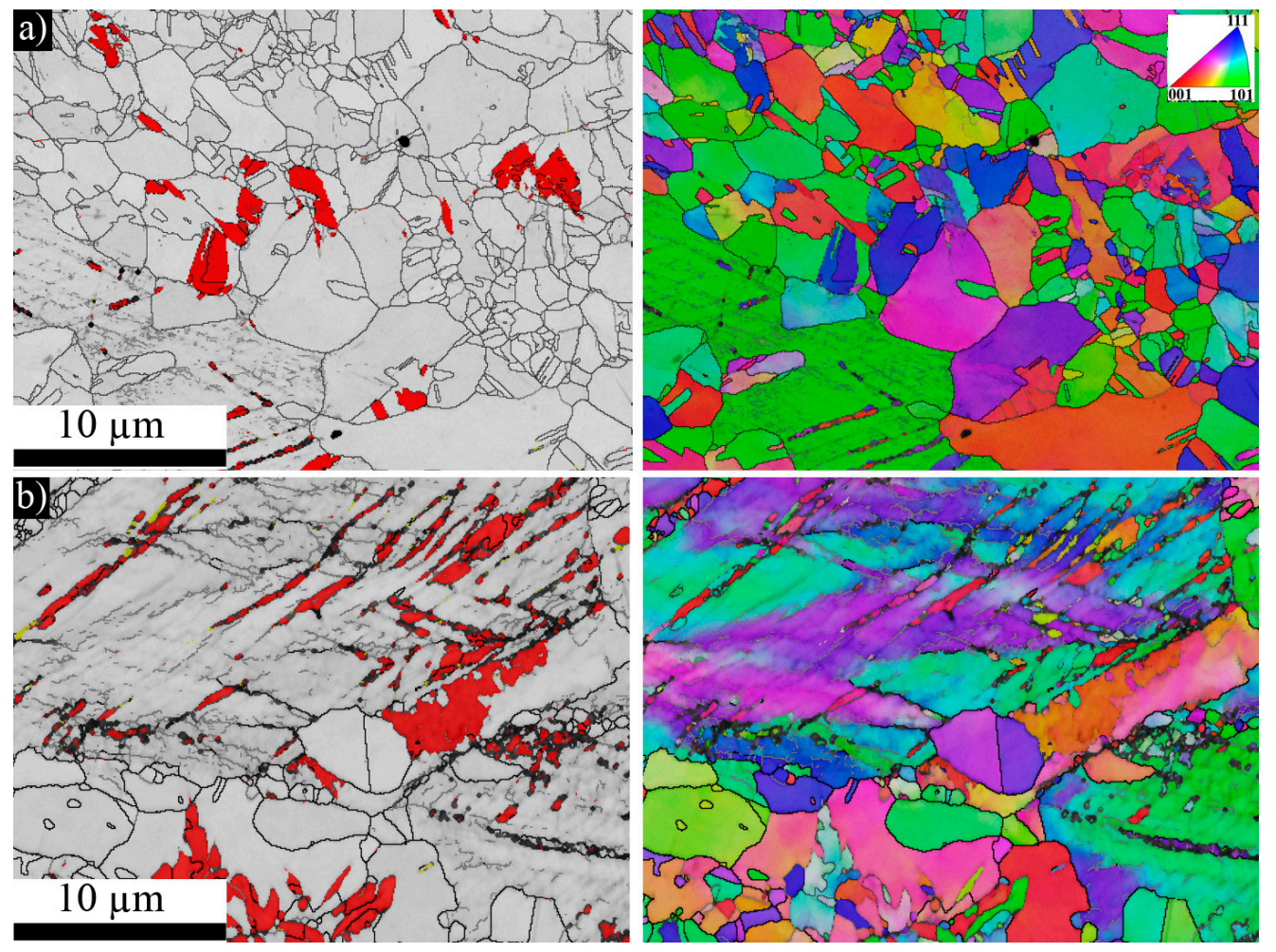

Figure 11. EBSD phase maps and IPF images of the reversed structures after exposure to $7 \%$ tensile strain (a) 900-1-32CR, (b) 800-10-32CR. Formation of the first DIM grains mainly in reddish and bluish medium-sized austenite grains and in a minor amount in shear bands in green grains.

We have to notice that even though the fraction of medium-sized grains is lower in the 750-0.1 structure than in its 900-1 counterpart at a given CR reduction, the former structure is much more unstable. Hence, the fraction and texture of the medium-sized grains cannot explain the stability difference between these structures created at these different annealing temperatures. The precipitation of $\mathrm{CrN}$ in the 750-0.1 structure seems to be the factor which also reduces the austenite stability in the 32CR structures, as confirmed earlier in the instance of the 63CR structures [30]. The mobility of all alloying elements in martensite is high, due to high defect concentration and pipe diffusion, shown to be 45 times higher than in the ferrite phase [35]. It was found that rolling deformation quite slightly affects the dislocation density of the martensite phase in Type 304 steel [36]. Consequently, we may conclude that the influence of CR reduction on the diffusion rates of alloying elements and the precipitation kinetics in the martensite is only minor, so that precipitation kinetics are very fast even after the low CR reduction.

\section{Conclusions}

The effect of the cold rolling (CR) reduction on reversed microstructures and their mechanical behavior in a 301LN stainless steel was investigated. Three CR reductions-32\%, 45\% and $63 \%-$ were applied to create two structures: a completely austenitic one obtained at $900{ }^{\circ} \mathrm{C}$ in $1 \mathrm{~s}$ and a partially reversed structure obtained at $750{ }^{\circ} \mathrm{C}$ in $0.1 \mathrm{~s}$. The main results and conclusions are as follows: 
- Decreasing the CR reduction reduces the general grain refinement in the reversion. At CR reductions of $32 \%$ and $45 \%$, the fraction of medium-sized grains (grain size $\geq 3 \mu \mathrm{m}$ ) is significant in both structures.

- The medium-sized austenite grains nucleate mainly in the slightly-deformed martensite and in a minor amount in the retained austenite; these fractions increase with a decrease in the $\mathrm{CR}$ reduction.

- Local disappearance of dislocations close to high-angle grain boundaries, leading to gradual evolution of subgrains to grains, seems to be the mechanisms of the formation of the medium-sized grains from shear-reversed austenite.

- In spite of a larger average grain size, the tensile properties of the reversed structures after the $32-45 \%$ CR reductions were practically equal to those after the $63 \%$ reduction. Increasing the fraction of retained austenite in the partially reversed structure balances the influence of an increasing fraction of medium-sized grains.

- The stability of the reversed austenite, formed at a given annealing temperature, under tensile straining, decreases with a decrease in the $\mathrm{CR}$ reduction.

- Medium-sized grains are the most unstable under tensile straining, which can be explained by their larger size than that of submicron grains formed from heavily-deformed martensite, and their orientation. The dependence of the fraction of slightly-deformed martensite, and thereby, that of medium-sized grains, on the CR reduction explains the influence of degree of CR on the stability of a certain structure. Also, the grain orientations between $\{111\}<u v w>$ and $\{100\}<u v w>$, favored by a low $C R$ reduction, reduce the austenite stability.

- The results indicate that CR reductions as low as $32-45 \%$, instead of $63 \%$, can be used in the manufacturing of a reversion-treated austenitic stainless steel of 301LN type with considerably refined grain structure and significantly enhanced tensile strength properties.

Acknowledgments: Antti Järvenpää acknowledges with gratitude the funding from Technology Industries of Finland Centennial Foundation Fund for the Association of Finnish Steel and Metal Producers and the Interreg Nord 2014-2020 - program as well as the continuous support from Outokumpu Company.

Author Contributions: Antti Järvenpää was responsible for mechanical testing, metallographic examinations, and data analysis. Matias Jaskari was responsible for metallographic and mechanical sample preparation. Pentti Karjalainen was the main author in writing the manuscript and drawing the conclusions.

Conflicts of Interest: The authors declare no conflict of interest.

\section{References}

1. Di Schino, A.; Salvatori, I.; Kenny, J.M. Effects of martensite formation and austenite reversion on grain refining of AISI 304 stainless steel. J. Mater. Sci. 2002, 37, 4561-4565. [CrossRef]

2. Di Schino, A.; Barteri, M.; Kenny, J.M. Development of ultra fine grain structure by martensitic reversion in stainless steel. J. Mater. Sci. Lett. 2002, 21, 751-753. [CrossRef]

3. Somani, M.C.; Juntunen, P.; Karjalainen, L.P.; Misra, R.D.K.; Kyröläinen, A. Enhanced mechanical properties through reversion in metastable austenitic stainless steels. Metall. Mater. Trans. A 2009, 40, 729-744. [CrossRef]

4. Järvenpää, A.; Karjalainen, L.P.; Jaskari, M. Effect of grain size on fatigue behaviour of Type 301LN stainless steel. Int. J. Fatigue 2014, 65, 93-98. [CrossRef]

5. Kisko, A.; Hamada, A.; Karjalainen, L.P.; Talonen, J. Microstructure and Mechanical Properties of Reversion Treated High Mn Austenitic 204Cu and 201 Stainless Steels, HMnS 2011; Paper B-19; Grand Hilton Hotel: Seoul, Korea, 2011.

6. Tomimura, K.; Takaki, S.; Tanimoto, S.; Tokunaga, Y. Optimal chemical composition in Fe-Cr-Ni alloys for ultra grain refining by reversion from deformation induced martensite. ISIJ Int. 1991, 31, 721-727. [CrossRef]

7. Takaki, S.; Tomimura, K.; Ueda, S. Effect of pre-cold-working on diffusional reversion of deformation induced martensite in metastable austenitic stainless steel. ISIJ Int. 1994, 34, 522-527. [CrossRef] 
8. Misra, R.D.K.; Nayak, S.; Mali, M.A.; Shah, J.S.; Somani, M.C.; Karjalainen, L.P. On the significance of nature of strain-induced martensite on phase-reversion-induced nanograined/ultrafine-grained austenitic stainless steel. Metall. Mater. Trans. A 2010, 41, 3-12. [CrossRef]

9. Misra, R.D.K.; Zhang, Z.; Venkatasurya, P.K.C.; Somani, M.C.; Karjalainen, L.P. Martensite shear phase reversion-induced nanograined/ultrafine-grained $\mathrm{Fe}-16 \mathrm{Cr}-10 \mathrm{Ni}$ alloy: The effect of interstitial alloying elements and degree of austenite stability on phase reversion. Mater. Sci. Eng. A 2010, 527, 7779-7792. [CrossRef]

10. Matsuoka, Y.; Iwasaki, T.; Nakada, N.; Tsuchiyama, T.; Takaki, S. Effect of grain size on thermal and mechanical stability of austenite in metastable austenitic stainless steel. ISIJ Int. 2013, 3, 1224-1230. [CrossRef]

11. Poulon-Quintin, A.; Brochet, S.; Vogt, J.-B.; Glez, J.-C.; Mithieux, J.-D. Fine grained austenitic stainless steels: The role of strain induced martensite and the reversion mechanism limitations. ISIJ Int. 2009, 49, $293-301$. [CrossRef]

12. Ravi Kumar, B.; Das, S.K.; Mahato, B.; Ghosh, R.N. Role of strain-induced martensite on microstructural evolution during annealing of metastable austenitic stainless steel. J. Mater. Sci. 2010, 45, 911-918. [CrossRef]

13. Maréchal, D. Linkage between Mechanical Properties and Phase Transformation in a 301LN Austenitic Stainless Steel. Ph.D. Thesis, The University of British Columbia, Vancouver, BC, Canada, 2011.

14. Rajasekhara, S.; Karjalainen, L.P.; Kyröläinen, A.; Ferreira, P.J. Microstructure evolution in nano/submicron grained AISI 301LN stainless steel. Mater. Sci. Eng. A 2010, 527, 1986-1996. [CrossRef]

15. Roy, B.; Kumar, R.; Das, J. Effect of cryorolling on the microstructure and tensile properties of bulk nano-austenitic stainless steel. Mater. Sci. Eng. A 2015, 631, 241-247. [CrossRef]

16. Yi, X.; He, T.; Wang, J.; Lu, Y.; Chen, L.; Ren, F.Z.; Liu, Y.; Volinsky, A.A. Cryorolling effect on microstructure and mechanical properties of Fe-25Cr-20Ni austenitic stainless steel. Mater. Des. 2015, 88, 398-405.

17. Ma, Y.; Jin, J.-E.; Lee, Y.-K. A repetitive thermomechanical process to produce nano-crystalline in a metastable austenitic steel. Scripta Mater. 2005, 52, 1311-1315. [CrossRef]

18. Behjati, P.; Kermanpur, A.; Karjalainen, L.P.; Järvenpää, A.; Jaskari, M.; Samaei Baghbadorani, H.; Najafizadeh, A.; Hamada, A. Influence of prior cold rolling reduction on microstructure and mechanical properties of a reversion annealed high-Mn austenitic steel. Mater. Sci. Eng. A 2016, 650, 119-128. [CrossRef]

19. Behjati, P.; Kermanpur, A.; Najafizadeh, A.; Samaei Baghbadorani, H.; Karjalainen, L.P.; Jung, J.-G.; Lee, Y.-K. Design of a new Ni-free austenitic stainless steel with unique ultrahigh strength-high ductility synergy. Mater. Des. 2014, 63, 500-507. [CrossRef]

20. Järvenpää, A.; Jaskari, M.; Man, J.; Karjalainen, L.P. Austenite stability in reversion-treated structures of a 301LN steel under tensile loading. Mater. Charact. 2017, 127, 12-26. [CrossRef]

21. Järvenpää, A.; Jaskari, M.; Man, J.; Karjalainen, L.P. Stability of grain-refined reversed structures in a 301LN austenitic stainless steel under cyclic loading. Mater. Sci. Eng. A 2017, 703, 280-292. [CrossRef]

22. Ravi Kumar, B.; Sharma, S. Recrystallization behavior of a heavily deformed austenitic stainless steel during iterative type annealing. Metall. Mater. Trans. A 2014, 45, 6027-6038. [CrossRef]

23. Kisko, A.; Hamada, A.S.; Talonen, J.; Porter, D.; Karjalainen, L.P. Effects of reversion and recrystallization on microstructure and mechanical properties of $\mathrm{Nb}$-alloyed low-Ni high-Mn austenitic stainless steels. Mater. Sci. Eng. A 2016, 657, 359-370. [CrossRef]

24. Misra, R.D.K.; Nayak, S.; Venkatasurya, P.K.C.; Ramuni, V.; Somani, M.C.; Karjalainen, L.P. Nanograined/ultrafine-grained structure and tensile deformation behavior of shear phase reversion-induced 301 austenitic stainless steel. Metall. Mater. Trans. A 2010, 41, 2162-2174. [CrossRef]

25. Talonen, J.; Aspegren, P.; Hänninen, H. Comparison of different methods for measuring strain induced $\alpha^{\prime}$-martensite content in austenitic steels. Mater. Sci. Technol. 2004, 20, 1506-1512. [CrossRef]

26. Beese, A.M.; Mohr, D. Identification of the direction-dependency of the martensitic transformation in stainless steel using in situ magnetic permeability measurements. Exp. Mech. 2011, 51, 667-676. [CrossRef]

27. Tomimura, K.; Takaki, S.; Tokunaga, Y. Reversion austenite mechanism from deformation induced martensite in metastable austenitic stainless steels. ISIJ Int. 1991, 31, 1431-1437. [CrossRef]

28. Lee, S.-J.; Park, Y.-M.; Lee, Y.-K. Reverse transformation mechanism of martensite to austenite in a metastable austenitic alloy. Mater. Sci. Eng. A 2009, 515, 32-37. [CrossRef]

29. Rajasekhara, S.; Ferreira, P.J.; Karjalainen, L.P.; Kyröläinen, A. Hall-Petch behavior in ultra-fine-grained AISI 301LN stainless steel. Metall. Mater. Trans. A 2007, 38, 1202-1210. [CrossRef] 
30. Järvenpää, A.; Jaskari, M.; Juuti, T.; Karjalainen, L.P. Demonstrating the effect of precipitation on mechanical stability of austenite in a reversion-treated 301LN stainless steel. Metals 2017, 7, 344. [CrossRef]

31. Weidner, A.; Glage, A.; Martin, S.; Man, J.; Klemm, V.; Martin, U.; Polák, J.; Rafaja, D.; Biermann, H. Microstructure of austenitic stainless steels of various phase stabilities after cyclic and tensile deformation. Int. J. Mater. Res. 2011, 102, 1374-1377. [CrossRef]

32. $\mathrm{Hu}, \mathrm{H}$. Texture of metals. Texture 1974, 1, 233-258. [CrossRef]

33. Hirsch, J.; Lücke, K. Overview No. 76. Mechanism of deformation and development of rolling textures in polycrystalline f.c.c. metals-I. Description of rolling texture development in homogeneous CuZn alloys. Acta Metall. 1988, 36, 2863-2882. [CrossRef]

34. Ravi Kumar, B.; Singh, A.K.; Mahato, B.; De, P.K.; Bandyopadhyay, N.R.; Bhattacharya, D.K. Deformation-induced transformation textures in metastable austenitic stainless steel. Mater. Sci. Eng. A 2006, 429, 205-211. [CrossRef]

35. Dmitrieva, O.; Ponge, D.; Inden, G.; Millán, J.; Choi, P.; Sietsma, J. Chemical gradients across phase boundaries between martensite and austenite in steel studied by atom probe tomography and simulation. Acta Mater. 2011, 59, 364-374. [CrossRef]

36. Shintani, T.; Murata, Y. Evaluation of the dislocation density and dislocation character in cold rolled Type 304 steel determined by profile analysis of X-ray diffraction. Acta Mater. 2011, 59, 4314-4322. [CrossRef]

(c) 2018 by the authors. Licensee MDPI, Basel, Switzerland. This article is an open access article distributed under the terms and conditions of the Creative Commons Attribution (CC BY) license (http://creativecommons.org/licenses/by/4.0/). 